\title{
Sensitivity of potential evapotranspiration to climate factors in forested mountainous watersheds
}

\author{
Fereshteh Ghiami-Shomami ${ }^{1}$, Kohzo Kawasaki ${ }^{2}$, Leonardo ${ }^{3}$, Seirou Shinoda ${ }^{3}$ and Yanyang Fan ${ }^{3}$ \\ ${ }^{I}$ Graduate School of Engineering, Department of Mechanical and Civil Engineering, Gifu University, Japan \\ ${ }^{2}$ Graduate School of Natural Science and Technology, Department of Civil Engineering, Gifu University, Japan \\ ${ }^{3}$ Faculty of Engineering, Department of Civil Engineering, Gifu University, Japan
}

\begin{abstract}
:
Estimation of reference evapotranspiration $\left(E T_{0}\right)$ is important in hydrological studies. As climate change is predicted to cause changes in water resources and agriculture sectors, the possible implications of changes in different climate variables on $E T_{0}$ need to be understood. Sensitivity analysis was employed to illustrate the effects of perturbation in meteorological parameters (maximum and minimum air temperature $\left(T_{\max }\right.$ and $\left.T_{\min }\right)$, sunshine hours $(n)$, maximum and minimum relative humidity $\left(R H_{\max }\right.$ and $\left.\left.R H_{\min }\right)\right)$ and wind speed $\left(u_{z}\right)$ on $E T_{0} . E T_{0}$ was calculated by The Food and Agriculture Organization of the United Nations (FAO) 56 Penman-Monteith approach using climate data from 1979-2017 for the Enbara and Futatsumori watersheds in forested mountain areas in Japan. We quantified the contributions of climatic factors to $E T_{0}$ at daily, monthly, seasonal and annual time scales. Daily results showed large fluctuations. According to the monthly and seasonal analysis, during warm seasons, $T_{\max }$ and $n$ had more influence on $E T_{0}$, especially in May, while for the cold seasons, $R H$ effect was dominant, especially in December. Based on the annual results, the factors most influencing $E T_{0}$ were $T_{\max }$ followed by $n, u_{z}, R H$ and $T_{\text {min }}$. We also found that the response of $E T_{0}$ to changes in climatic parameters differs for sites with different topographic and geographic characteristics.
\end{abstract}

KEYWORDS climate data; Penman-Monteith; reference evapotranspiration; sensitivity analysis; watershed; Gifu

\section{INTRODUCTION}

The issue of climate change has received considerable attention in recent years due to its potential to affect the precipitation, runoff and evapotranspiration components of the hydrological cycle (Attarod et al., 2015; Liang et al., 2008). Many natural disasters associated with changes in hydrological processes due to the climate change have led to major problems in Japan (Iizumi et al., 2012; Kawagoe et al., 2010; Mouri et al., 2012; Primark et al., 2009; Shiono et al., 2013). Japan is likely to experience more annual rainfall as well as increases in rainfall intensity and the number of days with rainfall greater than $50 \mathrm{~mm}$ in the future. Beside rainfall, Japan is also getting warmer with a $2-3^{\circ} \mathrm{C}$ rise is predicted for mean annual temperatures (JMA, 2005; Kato, 1996; Kurihara et al., 2005).

Among all components of the hydrological cycle, actual evapotranspiration $\left(E T_{\mathrm{C}}\right)$ is a major element which can be estimated from reference evapotranspiration $\left(E T_{0}\right)$ and crop coefficients $\left(K_{\mathrm{C}}\right)$. Values for $E T_{\mathrm{C}}$ are used in water resources planning and management, hydrological catchment models and irrigation. $E T_{0}$ is defined as the evapotranspiration of a hypothetical surface of green grass, which is actively growing and is not short of water, with an assumed crop height of $0.12 \mathrm{~m}$, a fixed surface resistance of $70 \mathrm{~s} \mathrm{~m}^{-1}$, and an albedo of 0.23 . In hydrological studies, reliable estimation of $E T_{0}$ is of critical importance and is required to analyze the water balance. Since $E T_{0}$ is dependent only on meteorological conditions, not the underlying surface, and is readily measurable or calculable, it can be used to reflect regional water-energy balance changes and the effect of climate change (Du et al., 2016; Gu et al., 2018).

Among different methods which have been developed to estimate $E T_{0}$, the Penman-Monteith model simplified by The Food and Agriculture Organization of the United Nations (FAO) Paper No. 56 (henceforward called FAO56$\mathrm{PM}$ ) is generally accepted to have high performance in terms of predicting $E T_{0}$ (FAO, 1998). This model has been commonly used globally due to its advantage in taking into account both thermodynamic and aerodynamic characteristics (Er-Raki et al., 2007, 2008; Jabloun and Sahli, 2008; Temesgen et al., 2005; Wright et al., 2000).

As the required input variables to apply FAO56-PM are relatively high, any sensor-based errors or bias in measurements can cause tremendous error in the outputs of the estimated $E T_{0}$ (DeJonge et al., 2015a). On the other hand, climate change is expected to make dramatic changes in the meteorological variables leading to changes in $E T_{0}$ (Irmak et al., 2006). Therefore, it is essential to understand the effect of perturbations in each climatic variable on $E T_{0}$ calculations, whether caused by sensor-based measurement errors or climate change. These objectives would be satisfied through sensitivity analysis (SA) which quantifies the dominant meteorological factors in estimating $E T_{0}$. The SA of $E T_{0}$ is needed to provide information on the relationship

Correspondence to: Fereshteh Ghiami-Shomami, Graduate School of Engineering, Department of Mechanical and Civil Engineering, Gifu University, Yanagido 1-1, Gifu 501-1193, Japan. E-mail: fereshteh. ghiami.sh@gmail.com 
between data availability and estimation accuracy of $E T_{0}$ (Hou et al., 2013) as well as determining the required accuracy for measuring climatic data (Irmak et al., 2006). Furthermore, it allows improvements in our understanding of the possible impact of climate change on the hydrological cycle by providing information about the connections between climatic conditions and $E T_{0}$ variability.

Several studies have assessed the sensitivity of $E T_{0}$ to climate variables (Debnath et al., 2015; DeJonge et al., 2015b; Mosaedi et al., 2017; Ndiaye et al., 2017). Using data from the U.S. Weather Bureau, Coleman and DeCoursey (1976) showed that, for winter months, relative humidity, and during summer, both solar radiation and temperature, control changes in all $E T_{0}$ equations. Piper (1989) selected a vast area covering different countries located between latitudes $25^{\circ} \mathrm{N}$ and $25^{\circ} \mathrm{S}$ and at altitudes of less than $500 \mathrm{~m}$. He concluded that errors in measurement of mean temperature would have a major effect on $E T_{0}$ estimation while the effect of wind speed, sunshine hours and wet bulb temperature measurement errors are similar and less significant. Sensitivity analysis of $E T_{0}$ performed in northwest China revealed that, in the mountainous area and during the cool months, vapor pressure has the most effect on $E T_{0}$ with the least sensitive factor during the year being mean air temperature (Zhang et al., 2010).

To the best of our knowledge, no study has investigated the sensitivity of $E T_{0}$ to the variation in climatic factors in different scenarios in Japan. In addition, available water resources, which are being affected by changes in hydrological processes, would be better managed if supported by information on the sensitivity of $E T_{0}$ to meteorological parameters. Considering this, and given that there are interactions between climatic parameters, which could be highly affected by global warming, SA of $E T_{0}$ is essential. Thus, the present study aimed to first determine the response of $E T_{0}$ to perturbations (all sorts of data errors, or actual climatic changes) in meteorological factors. Furthermore, the dominant climatic factor associated with seasonal and annual $E T_{0}$ changes were identified. Finally, the differences in sensitivity coefficients of each climatic variable at sites with different topographic and geographic characteristics were also clarified.

\section{METHODS}

This study was carried out in Enbara and Futatsumori (Kojima et al., 2013; Zainal et al., 2012) watersheds in forested mountainous areas located, respectively, in Yamagata and Nakatsugawa cities of Gifu prefecture, central Japan. We have been investigating the relationship between runoff properties and the characteristics of the forest environment in these watersheds. Enbara watershed was represented by the Japan Meteorological Agency (JMA) weather station at Tarumi (12 km away) and Futatsumori watershed by the Kurokawa station (9.2 km away) of (Figure 1). Considering the data quality and completeness, a 39-year (1979-2017) daily data set of maximum and minimum relative humidity $\left(R H_{\max }\right.$ and $\left.R H_{\min }\right)$, sunshine duration $(n)$, maximum and minimum temperatures $\left(T_{\max }\right.$ and $\left.T_{\min }\right)$ and wind speed $\left(u_{z}\right)$ for the selected stations were obtained from the Automated Meteorological Data Acquisition System (AMeDAS). The data of $u_{z}$ was observed at a height of 9.4 for Kurokawa station while Tarumi $u_{z}$ data was recorded at heights of 7.5 and 10 before and after 2010, respectively. Since relative humidity data has not been gathered at the abovementioned stations, a distance-based interpolation approach was applied to use neighboring stations' $R H$ data and esti-

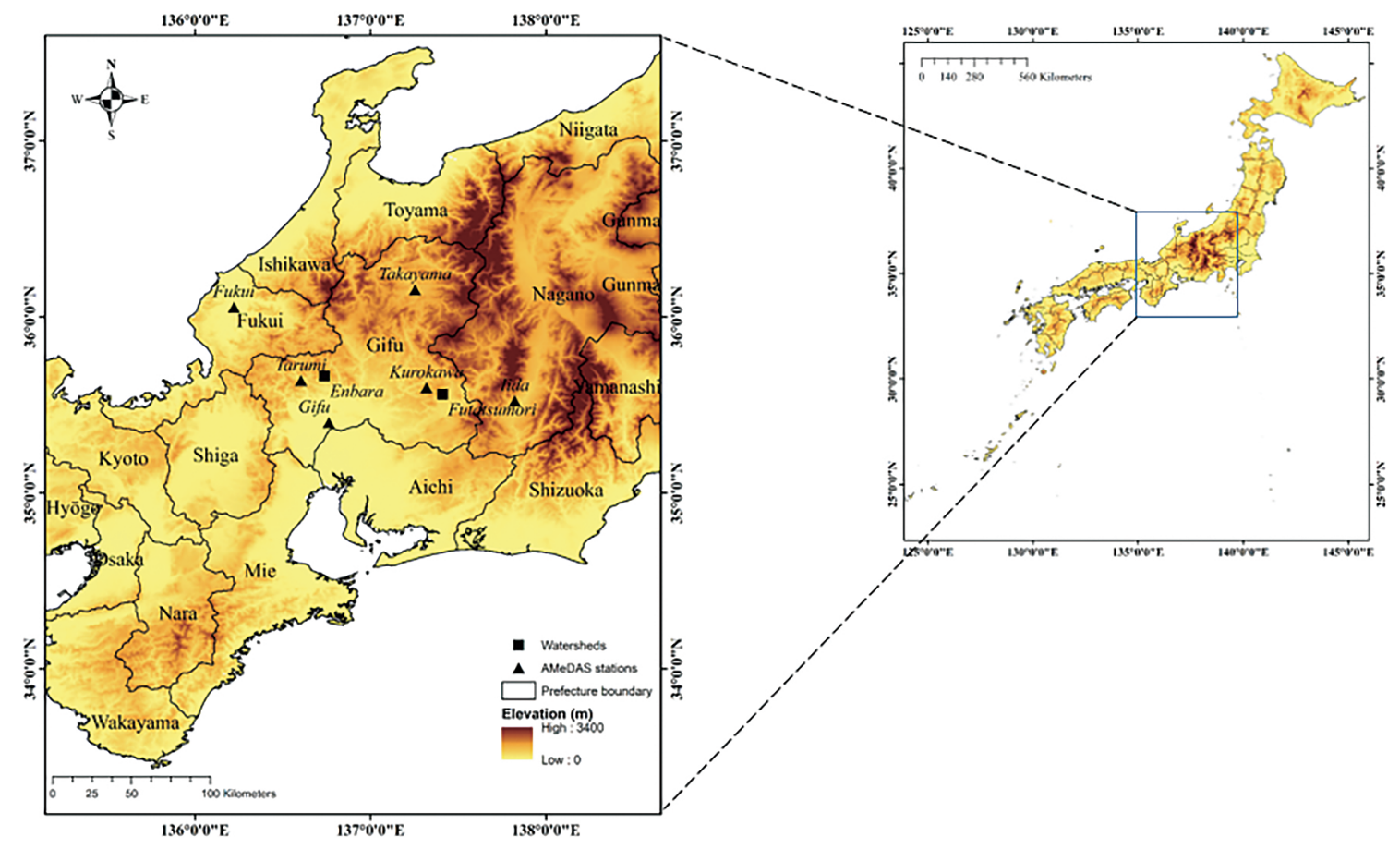

Figure 1. Location of AMeDAS stations and watersheds 
mate $R H$ at the selected stations. In this regard, Fukui, Gifu and Takayama data were used to estimate $R H$ at Enbara, and Iida, Gifu and Takayama data used for $R H$ at Futatsumori. Table I shows the geographical characteristics and the annually averaged meteorological variables calculated with these data.

\section{Reference evapotranspiration}

FAO suggests that the application of a standardized Penman-Monteith approach is preferred to predict $E T_{0}$ when the required data is available and reliable. The performance of FAO56-PM has been confirmed under different climate types and it has the major advantage of considering both meteorological and physiological crop variables in estimating $E T_{0}$ (Richard et al., 1998). The FAO56-PM equation to calculate daily $E T_{0}$ is given by:

$$
E T_{0}=\frac{0.408 \Delta\left(R_{n}-G\right)+\gamma \frac{900}{T+273} u_{2}\left(e_{s}-e_{a}\right)}{\Delta+\gamma\left(1+0.34 u_{2}\right)}
$$

where $E T_{0}$ is the reference evapotranspiration $\left(\mathrm{mm} \mathrm{d}^{-1}\right), T$ is the mean daily temperature $\left({ }^{\circ} \mathrm{C}\right), G$ is the soil heat flux (MJ $\left.\mathrm{m}^{-2} \mathrm{~d}^{-1}\right), R_{n}$ is the net Radiation $\left(\mathrm{MJ} \mathrm{m}^{-2} \mathrm{~d}^{-1}\right), \gamma$ is the psychrometric constant $\left(\mathrm{kPa}^{\circ} \mathrm{C}^{-1}\right), e_{s}$ is the mean saturation vapor pressure $(\mathrm{kPa}), e_{a}$ is the actual vapor pressure $(\mathrm{kPa})$, $\Delta$ is the slope of saturation vapor pressure curve $\left(\mathrm{kPa}^{\circ} \mathrm{C}^{-1}\right)$ and $u_{2}$ is the mean wind speed at height $2 \mathrm{~m}\left(\mathrm{~m} \mathrm{~s}^{-1}\right)$. The wind speed measured at heights other than $2 \mathrm{~m}$ can be adjusted according to the follow equation:

$$
u_{2}=u_{z} \frac{4.87}{\ln (67.8 h-5.42)}
$$

where $h$ is the height of the measurement above the ground surface $(\mathrm{m})$ and $u_{z}$ is the measured wind $\left(\mathrm{m} \mathrm{s}^{-1}\right)$. Also for standardization, $T$ for 24-hour periods is defined as the mean of the daily maximum $\left(T_{\max }\right)$ and minimum temperatures $\left(T_{\min }\right)$ rather than as the average of hourly temperature measurements (FAO, 1998).

\section{Sensitivity analysis}

Sensitivity analysis determines the expected change in the dependent variable (output) in response to changes in the independent variables (input) (McCuen, 1974). Various nondimensional forms of sensitivity coefficients $\left(C_{\mathrm{S}}\right)$ have been developed by calculating the partial derivative of the dependent variable $\left(E T_{0}\right)$ to the independent variables (climate factors). To identify the $E T_{0}$-related changes in response to changes in climatic variables, a mathematically-based approach was used to calculate the $C_{\mathrm{S}}$ of $E T_{0}$ (McCuen, 1974).

$$
C_{S}\left(x_{i}\right)=\lim _{\Delta x_{i} \rightarrow 0}\left(\frac{\Delta E T_{0} / E T_{0}}{\Delta x_{i} / x_{i}}\right)=\frac{\partial E T_{0}}{\partial x_{i}} \times \frac{x_{i}}{E T_{0}},
$$

where $x_{i}$ is the $i$ th meteorological parameter and $C_{\mathrm{S}}\left(x_{i}\right)$ is the $C_{\mathrm{S}}$ of $E T_{0}$ with regard to $x_{i}$. A negative (positive) $C_{\mathrm{S}}$ for a climatic factor suggests that $E T_{0}$ will inversely (similarly) respond to changes in the meteorological variable. The larger the $C_{\mathrm{S}}$, the more $E T_{0}$ is affected by that variable.

To achieve the objectives of our study, first, the variables were changed within a range of -30 to $+30 \%$ with an interval of 5\% (twelve scenarios) and the percent change in $E T_{0}$ was estimated (Goyal, 2004). Next, the percent changes in the meteorological variables were plotted against percent changes in the $E T_{0}$ as a sensitivity curve to calculate parameter sensitivity to the estimated $E T_{0}$. Finally, the $C_{\mathrm{S}}$ of each climate variable was calculated at daily, monthly, seasonal and annual scales. The first two scales are important in designing irrigation systems while information at an annual scale is required to manage water resources. On the other hand, any research findings on a seasonal scale would be valuable for designing water reservoirs. In this study, spring, summer, autumn, and winter were defined as March to May, June to August, September to November, and December to February, respectively.

\section{RESULTS AND DISCUSSION}

\section{Similar variation pattern of monthly $T_{\max } n$ and $E T_{0}$}

Figure 2 presents the temporal behavior of climate variables in the two watersheds at a monthly time scale. According to the air temperature $(T)$ pattern, which had a singlepeak, the maximum (minimum) values were observed in August (January or February). The largest value of $T_{\max }-$ $T_{\min }$ was recorded in April and May for both stations. This parameter dropped to its lowest value in January, considered one of the coldest months.

The patterns of $n$ and $E T_{0}$ were similar to those in $T_{\max }$ which showed an increase and then a reduction from January to December. The peak in $E T_{0}$ occured in May and August, at approximately $3 \mathrm{~mm} \mathrm{~d}^{-1}$. This coincides with dry conditions characterized by low $R H$ accompanied by high temperature, $u_{z}$ and $n$. On the other hand, $E T_{0}$ tended to reduce to a minimum value during the rainy season, particularly in June. This decline can be explained by the remarkable decrease in $n$ and increase in $R H$ during this month. The minimum value of $E T_{0}$ and $n$ mainly occurred during December and January. The difference between the maximum and minimum $E T_{0}$ varied more drastically in summer months than winter months.

\begin{tabular}{|c|c|c|c|c|c|c|c|c|c|c|}
\hline \multirow[b]{2}{*}{ Watersheds } & \multicolumn{3}{|c|}{ Coordinates } & \multirow{2}{*}{$\begin{array}{c}\text { Climate type } \\
\text { (Köppen-Geiger) }\end{array}$} & \multicolumn{6}{|c|}{ Annually averaged meteorological variables } \\
\hline & Latitude & Longitude & $\begin{array}{l}\text { Height above MSL } \\
(\mathrm{m})\end{array}$ & & $\begin{array}{l}T_{\max } \\
\left(\mathrm{C}^{\circ}\right)\end{array}$ & $\begin{array}{l}T_{\min } \\
\left(\mathrm{C}^{\circ}\right)\end{array}$ & $\begin{array}{c}n \\
\text { (hr) }\end{array}$ & $\begin{array}{c}u_{\mathrm{z}} \\
\left(\mathrm{m} \mathrm{s}^{-1}\right)\end{array}$ & $\begin{array}{c}R H_{\max } \\
(\%)\end{array}$ & $\begin{array}{l}R H_{\min } \\
(\%)\end{array}$ \\
\hline Enbara & $35^{\circ} 38^{\prime}$ & $136^{\circ} 36^{\prime}$ & 190 & $\mathrm{Cfa}$ & 17.5 & 8.7 & 3.7 & 0.9 & 86.1 & 52.3 \\
\hline Futatsumori & $35^{\circ} 35^{\prime}$ & $137^{\circ} 19^{\prime}$ & $\begin{array}{c}(1979-1998) 460 \\
\text { (1998-present) } 517\end{array}$ & $\mathrm{Cfa}$ & 17.6 & 6.9 & 5.1 & 0.7 & 87.2 & 49.9 \\
\hline
\end{tabular}

Table I. Geographical features of the synoptic stations along with their mean annual climate parameters for the period 19792017 

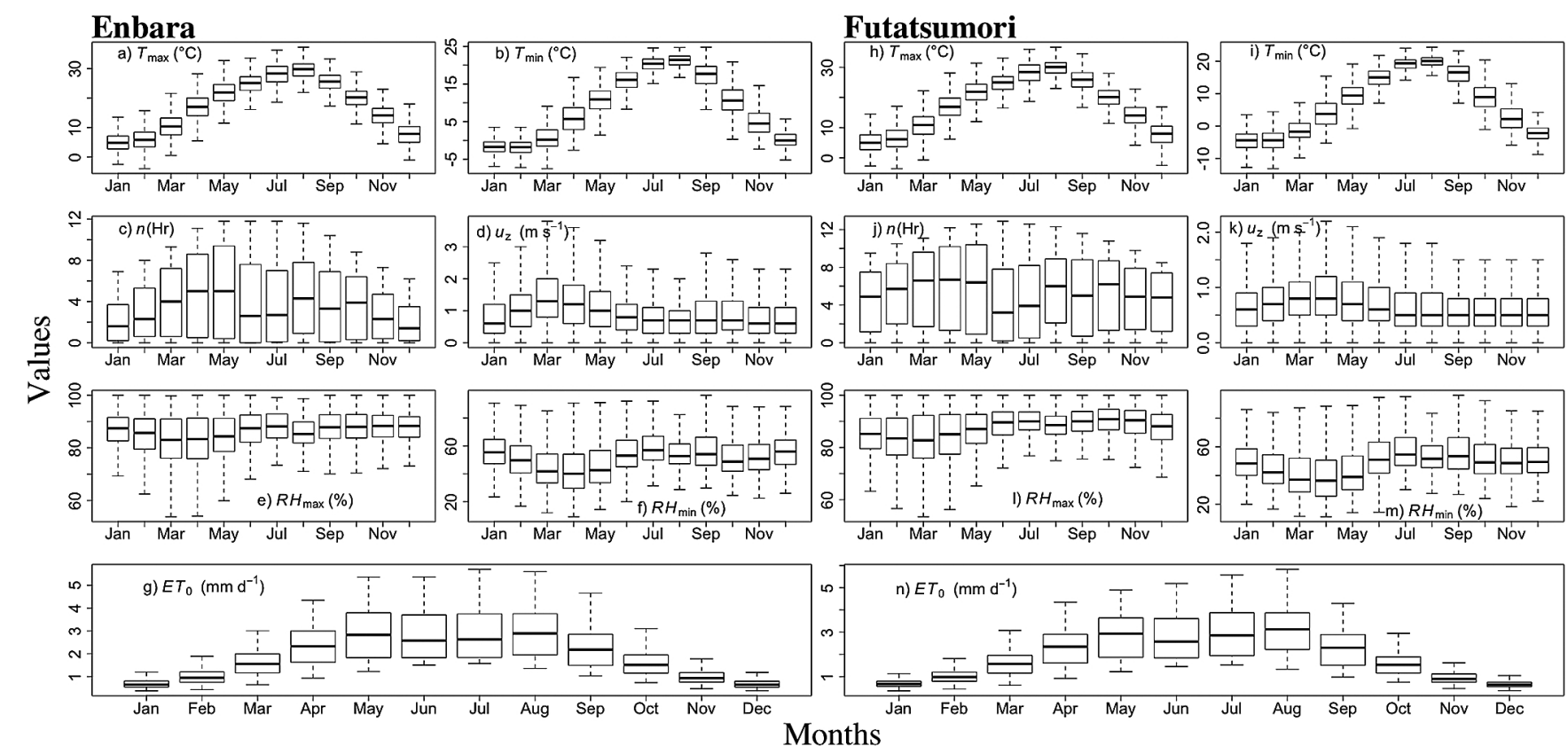

Figure 2. Box-and-whisker plot of temporal variation in monthly $E T_{0}$ and its main meteorological variables averaged for the period 1979-2017. a and h) maximum temperature, b and i) minimum temperature, $\mathrm{c}$ and $\mathrm{j}$ ) sunshine hours, $\mathrm{d}$ and $\mathrm{k}$ ) wind speed, e and l) maximum relative humidity, $\mathrm{f}$ and $\mathrm{m}$ ) minimum relative humidity, $\mathrm{g}$ and $\mathrm{n}$ ) evapotranspiration

The pattern of $R H$ was opposite to those of $n$ and $T$. The highest (lowest) value of $R H$ was recorded in cold and rainy seasons (spring). $u_{z}$ had quite small variation over the the year. The monthly peak of $u_{z}$ occurred in spring with a speed range of $0.5 \sim 2.0\left(\mathrm{~m} \mathrm{~s}^{-1}\right)$. In contrast, the minimum value of $u_{z}$ occurred in December $\left(\sim 0.5 \mathrm{~m} \mathrm{~s}^{-1}\right)$.

\section{$T_{\max }$ and $T_{\min }$ driving the most and least changes in $E T_{0}$ during the year}

Figure $\mathrm{S} 1$ shows the daily variation in $C_{\mathrm{S}}$ which helps us to grasp a comprehensive understanding on how $E T_{0}$ responds to each meteorological parameter during the year. The annual sensitivity curves of $E T_{0}$ are given in Figure S2. Sensitivity curves of $E T_{0}$ to weather parameters were typically linear. Large magnitude slopes indicate the most important metrological parameter affecting $E T_{0}$.

As shown in Figure $\mathrm{S} 1$, the $C_{\mathrm{S}}$ of all climate factors exhibited a large degree of daily fluctuation throughout the year. Although the temporal patterns in $T_{\max }$ and $T_{\min }$ were almost the same (Figure 2), the variations of their $\mathrm{C}_{\mathrm{S}}$ were different. At both stations, the sensitivity coefficients of $T_{\min }$ ranged from zero to 0.14 , which are significantly lower than all other variables. The variation in the $C_{\mathrm{S}}$ for $T_{\max }$ and $n$ was almost identical during the year with a pronounced temporal cycle. Negative $C_{\mathrm{S}}$ was obtained for $R H$, suggesting that an increase in $E T_{0}$ with a redecution in $R H$ and vice-versa. Daily variation patterns in $R H$ were opposite to those of $u_{z}$, but the peak of both variables evident during the same period.

According to Figure S2, at both stations the two factors most influencing $E T_{0}$ were $T_{\max }$ followed by $n$, whereas $T_{\min }$ did not have such a significant effect. In response to the increase in $T_{\max }, n$ and $T_{\min }$ by $+30 \%$, the percent change in $E T_{0}$ was about $11 \%, 8 \%$ and $2.5 \%$, respectively. At the
Enbara site, decreases and increases in $u_{z}$ by $5 \%$ to $30 \%$ favored a variation of $E T_{0}$ from $-0.7 \%$ to $-4.7 \%$ and $0.7 \%$ to $4.3 \%$. These results show that $E T_{0}$ was more affected by the reduction in $u_{z}$ than to by its increase. In contrast, increases in the other climate variables led to greater changes in $E T_{0}$ relative to their reduction.

Overall based on Figures $\mathrm{S} 1$ and S2, $T_{\max }$ and $n$ were the dominant factors driving the change in $E T_{0}$ during the year; Ambas and Baltas (2013) also concluded that $n$ and $T$ are major controlling factors in $E T_{0}$ changes. The increase in $T$ affects $E T_{0}$ primarily by increasing the capacity of air to hold water vapor, which is more notable during warm months. In this way the changes in $T_{\max }$ or $n$ due to global warming will lead to considerable changes in $E T_{0}$. Furthermore, among the six climate variables, $T_{\min }$ had the least effect on $E T_{0}$ and its $C_{\mathrm{S}}$ showed small alteration during the year. Similar results were reported by Irmak et al. (2006).

\section{$E T_{0}$ affected most by $T_{\max }$ and $n$ during warm period} and $R H$ and $u_{z}$ in cool period

Monthly $C_{\mathrm{S}}$ for each variable are given in Table II to clarify the effect of changes in each climatic factors on $E T_{0}$ as a function of month. Figure 3 also shows seasonal differences in $C_{\mathrm{S}}$ for each climate factor. Since the $E T_{0}$ values were generally higher during the warm months as a result of increased $n$ and $T$ (Figure 2), the percentage change in $E T_{0}$ was markedly influenced by $T_{\max }$ and $n$ from March to November at both stations (Table II). As shown in Figure 3, the minimum and maximum values of $C_{\mathrm{S}}$ for $T_{\max }$ and $n$ were found in winter and summer, respectively. While $C_{\mathrm{S}}$ of $T_{\max }$ for all seasons ranged between 0.16 and 0.35 , which is quite strong, $C_{\mathrm{S}}$ for $T_{\min }$ varied between 0.02 to 0.12 (Table II and Figure S1) from winter to summer, suggesting that $T_{\min }$ was less influential on $E T_{0}$ in all seasons. In con- 
Table II. Monthly averaged sensitivity coefficients for individual meteorological factors

\begin{tabular}{|c|c|c|c|c|c|c|c|c|c|c|c|c|c|}
\hline \multirow{2}{*}{ Watersheds } & \multirow{2}{*}{ Variables } & \multicolumn{12}{|c|}{ Months } \\
\hline & & Jan & Feb & Mar & Apr & May & Jun & Jul & Aug & Sep & Oct & Nov & Dec \\
\hline \multirow[t]{6}{*}{ Enbara } & $T_{\max }$ & 0.13 & 0.16 & 0.26 & 0.36 & 0.38 & 0.35 & 0.34 & 0.37 & 0.38 & 0.38 & 0.31 & 0.19 \\
\hline & $T_{\min }$ & 0.03 & 0.03 & 0.02 & 0.05 & 0.08 & 0.10 & 0.13 & 0.13 & 0.11 & 0.07 & 0.04 & 0.02 \\
\hline & $n$ & 0.04 & 0.10 & 0.16 & 0.20 & 0.23 & 0.21 & 0.22 & 0.27 & 0.20 & 0.15 & 0.06 & 0.01 \\
\hline & $u_{\mathrm{z}}$ & 0.20 & 0.19 & 0.19 & 0.16 & 0.13 & 0.10 & 0.08 & 0.10 & 0.12 & 0.18 & 0.22 & 0.22 \\
\hline & $R H_{\min }$ & -0.28 & -0.26 & -0.22 & -0.17 & -0.14 & -0.13 & -0.12 & -0.10 & -0.16 & -0.20 & -0.25 & -0.30 \\
\hline & $R H_{\text {max }}$ & -0.28 & -0.26 & -0.22 & -0.17 & -0.13 & -0.13 & -0.12 & -0.10 & -0.15 & -0.19 & -0.23 & -0.28 \\
\hline \multirow[t]{6}{*}{ Futatsumori } & $T_{\max }$ & 0.14 & 0.17 & 0.25 & 0.33 & 0.36 & 0.34 & 0.34 & 0.38 & 0.36 & 0.36 & 0.31 & 0.20 \\
\hline & $T_{\min }$ & 0.06 & 0.06 & 0.04 & 0.04 & 0.07 & 0.10 & 0.13 & 0.14 & 0.12 & 0.08 & 0.03 & 0.03 \\
\hline & $n$ & 0.06 & 0.16 & 0.22 & 0.26 & 0.27 & 0.23 & 0.27 & 0.33 & 0.27 & 0.22 & 0.10 & 0.02 \\
\hline & $u_{\mathrm{z}}$ & 0.21 & 0.17 & 0.15 & 0.13 & 0.11 & 0.09 & 0.07 & 0.09 & 0.09 & 0.13 & 0.19 & 0.23 \\
\hline & $R H_{\min }$ & -0.21 & -0.17 & -0.14 & -0.12 & -0.11 & -0.12 & -0.11 & -0.09 & -0.12 & -0.13 & -0.18 & -0.21 \\
\hline & $R H_{\max }$ & -0.18 & -0.15 & -0.13 & -0.11 & -0.09 & -0.11 & -0.10 & -0.08 & -0.10 & -0.11 & -0.15 & -0.18 \\
\hline
\end{tabular}
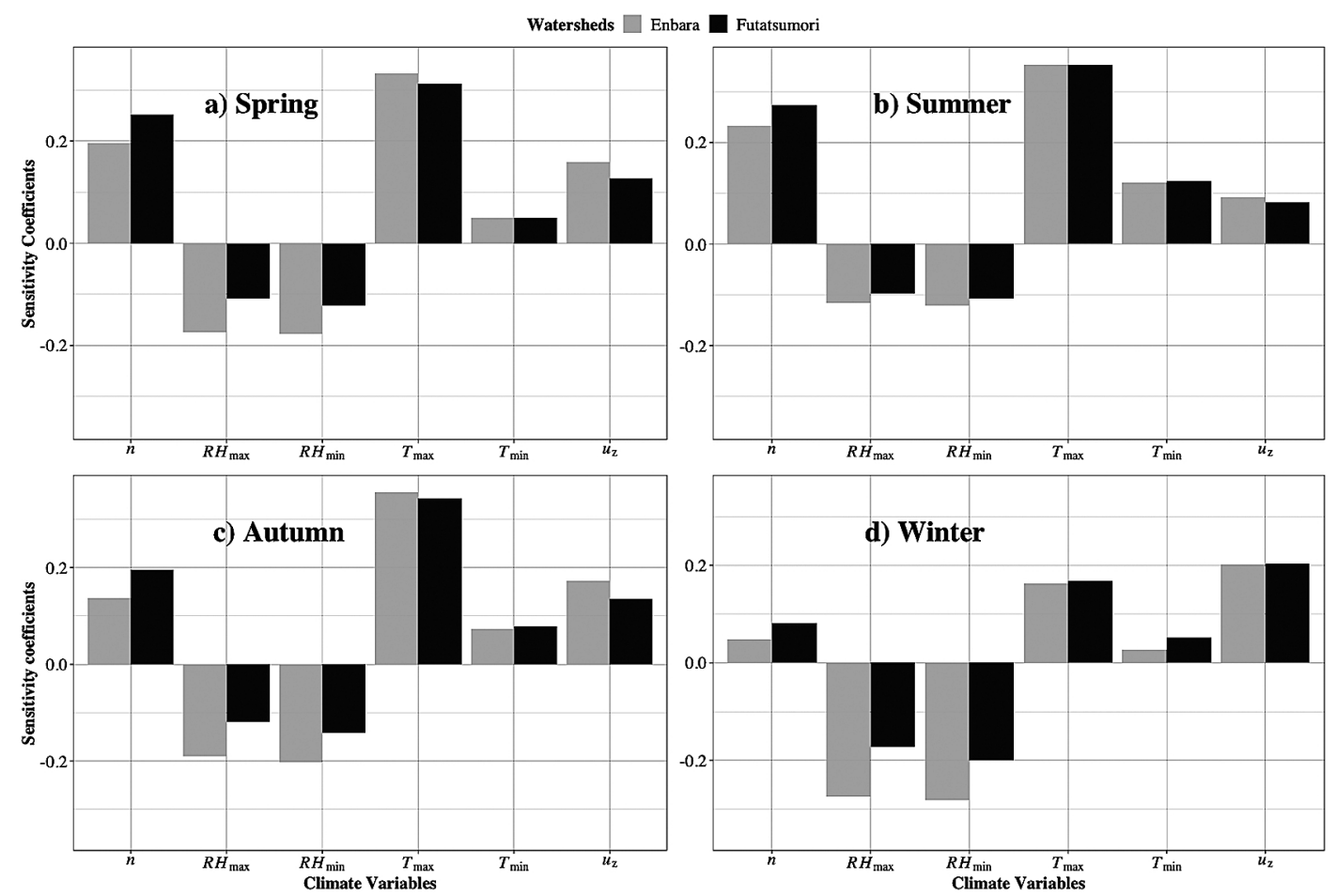

Figure 3. Sensitivity coefficients for the two watersheds for a) Spring, b) Summer, c) Autumn and d) Winter

trast to $T$, humidity increased in the cold months as well as the rainy season and decreased in the spring (Figure 2). As seen in Table II, the $C_{\mathrm{S}}$ of $R H$ was similarly strongly negative during the cold months, indicating that $E T_{0}$ was most affected by $R H$ during the winter time; this is in accordance with the findings of Coleman and DeCoursey (1976). $R H$ was a major limiting factor in $E T_{0}$, due to negative $C_{\mathrm{S}}$, confirming that climate change might have less impacts if warming is accompanied with higher humidity (Zeng and Heilman, 1997).

The effect of $R H$ and $u_{z}$ on $E T_{0}$ was most dominant from
December to February while insignificant impacts of these variables were evident from June to August (Table II). Wind flows likely exchange the moist air very quickly with dry air, notably during spring and winter in our study area (Figure 2), and makes $E T_{0}$ more sensitive to $u_{z}$ during these periods in comparison with other seasons (Ghafouri-Azar et al., 2018) (Figure 3).

In general, for both sites, the sensitivity of $E T_{0}$ to climatic variables was more significant during October and May. Changes in $E T_{0}$ during warm months, especially in spring and summer, appeared to be mostly controlled by 
a) Enbara

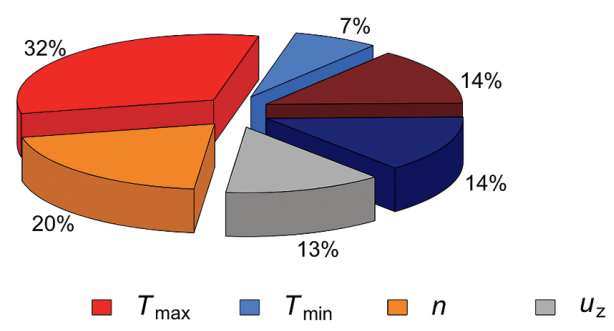

b) Futatsumori

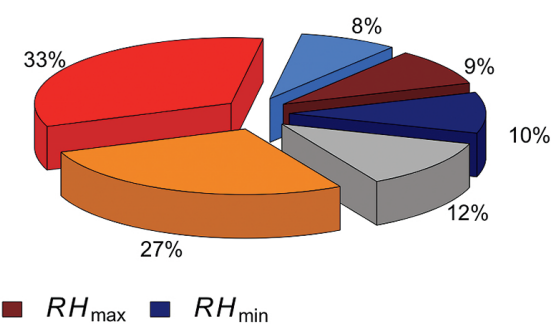

Figure 4. Comparison of annual relative influence of climate variables on $E T_{0}$ at a) Enbara and b) Futatsumori watersheds

$T_{\max }$ and $n$ whereas in cold months $R H$ and $u_{z}$ were the primary factors, especially in the winter season. This is because of the reduction in the energetic term, which makes the aerodynamic term more significant, resulting in increases in the $C_{\mathrm{S}}$ for $R H$ and $u_{z}$ during the cold months. This result suggests that the response of $E T_{0}$ to climate change will vary with season.

\section{Dominant effect of aerodynamic term in Enbara and Energy term in Futatsumori}

It has already been mentioned that all variables showed the same variation patterns in $C_{\mathrm{S}}$ at both sites (Figure 2). However, the results at Futatsumori were somewhat different from those at Enbara. This is more evident in the comparison of their seasonal $C_{\mathrm{S}}$ (Figure 3 ) and also the annual relative influence of climate variables on $E T_{0}$ at the two stations (Figure 4).

As seen in Figure 4, the energy term, measured by $n$, seemed to have more influence on $E T_{0}$ at Futatsumori (27\%) compared to Enbara (20\%) similar to the seasonal comparison of $C_{\mathrm{S}}$ (Figure 3). On the other hand, $E T_{0}$ at Enbara, which typically experiences wind with higher speed than Futatsumori (Figure 2 and Table I), was more affected by the aerodynamic term measured by $u_{z}$; there $R H$ $(13 \%, 14 \%)$ was higher than Futatsumori $(12 \%, 10 \%)$ (Figures 3 and 4).

Comparison between the two watersheds suggests that $E T_{0}$ is differently sensitive to climatic parameters at sites with different topographic and geographic characteristics. The Enbara watershed is located at the boundary of a plain and mountain area which changes the heat transfer processes, compared to the Futatsumori watershed which has characteristics of a uniform mountainous area. This difference caused non-matching patterns of $n$ and $T_{\max }$ at Enbara (Figure S1). Also owing to the geographic situation in which the Futatsumori watershed is located, clearer skies and more sunshine are usually observed (Figure 3), causing weaker (stronger) $R H(n)$ impacts on $E T_{0}$ at this site compared to the Enbara watershed.

\section{CONCLUSIONS}

$E T_{0}$, which is one of the most important hydrological and meteorological variables, can be used as an excellent indicator of hydroclimatic change (Du et al., 2016). In light of this to obtain a better understanding of the factors affecting
$E T_{0}$ behavior this paper conducted SA using six daily climatic variables from two watersheds in Gifu prefecture of Japan over a 39 year interval. This area was chosen based on prior research on the assessment of climate change impacts on hydrological process, using observed hydrological data sets from two watersheds. For the purpose of this study, $C_{\mathrm{S}}$ for each climate factor were derived to help us evaluate the impact of changes in the measured meteorological variables on the estimated $E T_{0}$. Also, the relative influence of each meteorological parameter on $E T_{0}$ in the two watersheds was compared.

The results of SA showed that $E T_{0}$ was highly sensitive to both $T_{\max }$ and $n$, especially in May, such that accurate estimation of these parameters is vital. For the cold seasons, the aerodynamic term measured by $R H$ was the most influential factors for $E T_{0}$, suggesting that $E T_{0}$ will respond differently to changes in climate during the warm and cold seasons. Comparison of the two watersheds revealed that the sensitivity of FAO56-PM estimates of evapotranspiration to different input data and parameters is dependent on topographic and geographic characteristics.

Since increases in $E T_{0}$ values would affect water budgets, this work may contribute to more appropriate climate change strategies that could be particularly well adapted to vulnerable sectors or areas. Future research could use these findings as a theoretical basis to examine the response of hydrological process to climate change.

\section{ACKNOWLEDGMENTS}

We are grateful to the observers of JMA for providing us with the requisite measurements.

\section{SUPPLEMENTS}

Figure S1. Mean daily sensitivity coefficient

Figure S2. Percent changes in $E T_{0}$ with respect to changes in climatic variables in annual time scale, Enbara (soild) and Futatsumori (dashed)

\section{REFERENCES}

Attarod P, Kheirkhah F, Khalighi Sigaroodi S, Sadeghi SMM. 2015. Sensitivity of Reference Evapotranspiration to Global 
Warming in the Caspian Region, North of Iran. Journal of Agricultural Science and Technology 17: 869-883.

Coleman G, DeCoursey DG. 1976. Sensitivity and model variance analysis applied to some evaporation and evapotranspiration models. Water Resources Research 12: 873-879. DOI: 10.1029/WR012i005p00873.

Debnath S, Adamala S, Raghuwanshi NS. 2015. Sensitivity Analysis of FAO-56 Penman-Monteith Method for Different Agro-ecological Regions of India. Environmental Processes 2: 689-704. DOI: 10.1007/s40710-015-0107-1.

DeJonge KC, Ahmadi M, Ascough JC, Kinzli KD. 2015a. Sensitivity analysis of reference evapotranspiration to sensor accuracy. Computers and Electronics in Agriculture 110: 176-186. DOI: 10.1016/J.COMPAG.2014.11.013.

DeJonge KC, Ahmadi M, Ascough JC, Kinzli KD. 2015b. Sensitivity analysis of reference evapotranspiration to sensor accuracy. Computers and Electronics in Agriculture 110: 176-186. DOI: 10.1016/J.COMPAG.2014.11.013.

Du C, Yu J, Wang P, Zhang Y. 2016. Reference Evapotranspiration Changes: Sensitivities to and Contributions of Meteorological Factors in the Heihe River Basin of Northwestern China (1961-2014). Advances in Meteorology 2016: 1-17. DOI: $10.1155 / 2016 / 4143580$.

Er-Raki S, Chehbouni A, Guemouria N, Duchemin B, Ezzahar J, Hadria R. 2007. Combining FAO-56 model and groundbased remote sensing to estimate water consumptions of wheat crops in a semi-arid region. Agricultural Water Management 87: 41-54. DOI: 10.1016/J.AGWAT.2006.02.004.

Er-Raki S, Chehbouni A, Hoedjes J, Ezzahar J, Duchemin B, Jacob F. 2008. Improvement of FAO-56 method for olive orchards through sequential assimilation of thermal infraredbased estimates of ET. Agricultural Water Management 95: 309-321. DOI: 10.1016/J.AGWAT.2007.10.013.

FAO. 1998. Crop evapotranspiration - Guidelines for computing crop water requirements. FAO-No. 56, FAO, Rome.

Ghafouri-Azar M, Bae DH, Kang SU. 2018. Trend Analysis of Long-Term Reference Evapotranspiration and Its Components over the Korean Peninsula. Water 10: 1373. DOI: $10.3390 /$ w10101373.

Goyal RK. 2004. Sensitivity of evapotranspiration to global warming: a case study of arid zone of Rajasthan (India). Agricultural Water Management 69: 1-11. DOI: 10.1016/ J.AGWAT.2004.03.014.

Gu R, Zhang D, Liao A, Shen H, Zhao X, Pan J. 2018. On the Attribution of Changing Reference Evapotranspiration in a Coastal Area of China. Atmosphere 9: 1-9. DOI: 10.3390/ atmos 9010009.

Hou L, Zou S, Xiao H, Yang Y. 2013. Sensitivity of the reference evapotranspiration to key climatic variables during the growing season in the Ejina oasis northwest China. Springerplus 2: 1-6. DOI: 10.1186/2193-1801-2-S1-S4.

Iizumi T, Takayabu I, Dairaku K, Kusaka H, Nishimori M, Sakurai G, Ishizaki NN, Adachi SA, Semenov MA. 2012. Future change of daily precipitation indices in Japan: A stochastic weather generator-based bootstrap approach to provide probabilistic climate information. Journal of Geophysical Research 117: 1-19. DOI: 10.1029/ 2011JD017197.

Irmak S, Payero JO, Martin DL, Irmak A, Howell TA. 2006. Sensitivity Analyses and Sensitivity Coefficients of Standardized Daily ASCE-Penman-Monteith Equation. Journal of Irrigation and Drainage Engineering 132: 564-578. DOI:
10.1061/(ASCE)0733-9437(2006)132:6(564).

Jabloun M, Sahli A. 2008. Evaluation of FAO-56 methodology for estimating reference evapotranspiration using limited climatic data: Application to Tunisia. Agricultural Water Management 95: 707-715. DOI: 10.1016/J.AGWAT.2008.01. 009.

Japan Meteorological Agency. 2005. Global warming projection, 6, with the RCM20 and UCM (in Japanese).

Kato H. 1996. A Statistical Method for Separating Urban Effect Trends from Observed Temperature Data and its Application to Japanese Temperature Records. Journal of the Meteorological Society of Japan Ser. II 74: 639-653. DOI: 10.2151/ jmsj1965.74.5_639.

Kawagoe S, Kazama S, Sarukkalige PR. 2010. Probabilistic modelling of rainfall induced landslide hazard assessment. Hydrology and Earth System Sciences 14: 1047-1061. DOI: 10.5194/hess-14-1047-2010.

Kojima T, Zainal E, Oike H, Ohashi K, Shinoda S. 2013. Evaluation of Green Dam in a Forested Small Catchment with Long Term Hydrological Data and Tank Model. Journal of Japan Society of Civil Engineers, Ser. G (Environmental Research) 69: 137-144. DOI: 10.2208/jscejer.69.I_137.

Kurihara K, Ishihara K, Sasaki H, Fukuyama Y, Saitou H, Takayabu I, Murazaki K, Sato Y, Yukimoto S, Noda A. 2005. Projection of Climatic Change over Japan Due to Global Warming by High-Resolution Regional Climate Model in MRI. SOLA 1: 97-100. DOI: 10.2151/sola. 2005-026.

Liang L, Li L, Zhang L, Li J, Li B. 2008. Sensitivity of penmanmonteith reference crop evapotranspiration in Tao'er River Basin of northeastern China. Chinese Geographical Science 18: 340-347. DOI: 10.1007/s11769-008-0340-x.

McCuen RH. 1974. A sensitivity and error analysis CF procedures used for estimating evaporation. Journal of the American Water Resources Association 10: 486-497. DOI: 10.1111/j. 1752-1688.1974.tb00590.x.

Mosaedi A, Ghabaei Sough M, Sadeghi SH, Mooshakhian Y, Bannayan M. 2017. Sensitivity analysis of monthly reference crop evapotranspiration trends in Iran: a qualitative approach. Theoretical and Applied Climatology 128: 857873. DOI: 10.1007/s00704-016-1740-y.

Mouri G, Shinoda S, Golosov V, Shiiba M, Hori T, Kanae S, Takizawa S, Oki T. 2012. Ecological and hydrological responses to climate change in an urban-forested catchment, Nagara River basin, Japan. Urban Climate 1: 40-54. DOI: 10.1016/J.UCLIM.2012.08.002.

Ndiaye PM, Bodian A, Diop L, Djaman K. 2017. Sensitivity Analysis of the Penman-Monteith Reference Evapotranspiration to Climatic Variables: Case of Burkina Faso. Journal of Water Resource and Protection 9: 1364-1376. DOI: 10.4236/jwarp.2017.912087.

Piper BS. 1989. Sensitivity of Penman estimates of evaporation to errors in input data. Agricultural Water Management 15: 279-300. DOI: 10.1016/0378-3774(89)90021-8.

Primark RB, Higuchi H, Miller-Rushing AJ. 2009. The impact of climate change on cherry trees and other species in Japan. Biological Conservation 142: 1943-1949. DOI: 10.1016/ J.BIOCON.2009.03.016.

Shiono T, Ogawa S, Miyamoto T, Kameyama K. 2013. Expected impacts of climate change on rainfall erosivity of farmlands in Japan. Ecological Engineering 61: 678-689. DOI: 10.1016/J.ECOLENG.2013.03.002. 
Temesgen B, Eching S, Davidoff B, Frame K. 2005. Comparison of Some Reference Evapotranspiration Equations for California. Journal of Irrigation and Drainage Engineering 131: 73-84. DOI: 10.1061/(ASCE)0733-9437(2005)131:1(73).

Wright JL, Allen RG, Howell TA. 2000. Conversion between evapotranspiration references and methods. National irrigation symposium. proceedings of the 4th Decennial Symposium November 14-16, 2000 Arizona, Phoenix, USA; 251259.

Zainal E, Ohashi K, Sakawai M, Kojima T, Shinoda S. 2012. Long term variable properties of runoff process in a moun- tainous forested catchment. Advances in River Engineering 18: 471-476.

Zeng W, Heilman JL. 1997. Sensitivity of evapotranspiration of cotton and sorghum in west Texas to changes in climate and $\mathrm{CO}_{2}$. Theoretical and Applied Climatology 57: 245-254. DOI: $10.1007 / \mathrm{BF} 00863616$.

Zhang X, Kang S, Zhang L, Liu J. 2010. Spatial variation of climatology monthly crop reference evapotranspiration and sensitivity coefficients in Shiyang river basin of northwest China. Agricultural Water Management 97: 1506-1516. DOI: $10.1016 /$ j.agwat.2010.05.004. 